\title{
A comparison of early versus late initiation of renal replacement therapy for acute kidney injury in critically ill patients: an updated systematic review and meta- analysis of randomized controlled trials
}

Xiao-mei Yang ${ }^{1+}$, Guo-wei Tu ${ }^{1+}$, Ji-li Zheng ${ }^{2}$, Bo Shen ${ }^{3}$, Guo-guang Ma', Guang-wei Hao', Jian Gao ${ }^{4} 5^{*}$ and Zhe Luo ${ }^{1 *}$

\begin{abstract}
Background: To investigate the impact of timing the initiation of renal replacement therapy (RRT) on clinical outcomes in critically ill patients with acute kidney injury (AKI), focusing on the randomized controlled trials (RCTs) in this field.

Methods: The PubMed, EMBASE and Cochrane databases were searched between January 1, 1985, and June 30, 2016, to identify randomized trials that assessed the timing of initiation of RRT in patients with AKI.

Results: Nine RCTs, with a total of 1636 patients, were enrolled in this meta-analysis. A pooled analysis of the studies indicated no mortality benefit with "early" RRT, with an RR of $0.98(95 \% \mathrm{Cl} 0.78$ to $1.23, P=0.84)$. There was no significant difference in intensive care unit (ICU) length of stay (LOS) or hospital LOS between the early and late RRT groups for survivors or nonsurvivors. Pooled analysis also demonstrated no significant change in renal function recovery (RR $1.02,95 \% \mathrm{Cl} 0.88$ to $1.19,12=59 \%$ ), RRT dependence (RR $0.76,95 \% \mathrm{Cl} 0.42$ to 1.37 , $12=0 \%$ ), duration of RRT (Mean difference $1.43,95 \% \mathrm{Cl}-1.75$ to $4.61,12=78 \%$ ), renal recovery time (Mean difference 0.73 , $95 \% \mathrm{Cl}-2.09$ to $3.56,12=70 \%$ ) or mechanical ventilation time (Mean difference $-0.95,95 \% \mathrm{Cl}-3.54$ to $1.64,12=64 \%$ ) between the early and late RRT groups. We found no significant differences in complications between the groups.

Conclusions: Our meta-analysis revealed that the "early" initiation of RRT in critically ill patients did not result in reduced mortality. Pooled analysis of secondary outcomes also showed no significant difference between the early and late RRT groups. More well-designed and large-scale trials are expected to confirm the result of this meta-analysis.
\end{abstract}

Keywords: Renal replacement therapy, Timing, Acute kidney injury

\section{Background}

Acute kidney injury (AKI) is a common complication of critical illness that carries high morbidity and mortality rates. Among patients with AKI, approximately $20 \%$ require renal replacement therapy (RRT) $[1,2]$. Apart from the

\footnotetext{
* Correspondence: gao.jian@zs-hospital.sh.cn; luo.zhe@zs-hospital.sh.cn ${ }^{\dagger}$ Equal contributors

${ }^{4}$ Department of Nutrition, Zhongshan Hospital, Fudan University, Shanghai 200032, People's Republic of China

'Department of Critical Care Medicine, Zhongshan Hospital, Fudan University, Shanghai 200032, People's Republic of China

Full list of author information is available at the end of the article
}

modality, dialysis dose and anticoagulation, the optimal time to start RRT is considered an important determinant of the outcome of critically ill patients receiving RRT [3].

There are huge variations in the timing of RRT initiation in critically ill patients in the real world, based on the data from large randomized controlled trials (RCTs) $[4,5]$. Although the early initiation of RRT was reported to be beneficial in critically ill patients with AKI [6,7], this might expose patients to unnecessary RRT. Several meta-analyses have been published regarding the optimal timing of RRT initiation that achieved conflicting 
conclusions [8-11]. The paucity of RCTs involved in the meta-analysis precluded the establishment of definitive conclusions because non-RCTs may exaggerate the magnitude of the effect due to intrinsic and external factors. Moreover, the secondary outcomes, including renal function recovery, RRT dependence and mechanical ventilation time, have not been carefully studied in previous meta-analyses.

Recently, two well-designed RCTs were issued to evaluate the outcome of different strategies for RRT $[12,13]$. The Artificial Kidney Initiation in Kidney Injury (AKIKI) trial demonstrated that mortality at 60 days was comparable between the groups (48.5\% in the early-strategy group and $49.7 \%$ in the delayed-strategy group) [12]. In contrast, the ELAIN randomized clinical trial revealed that the early initiation of RRT significantly reduced the 90-day mortality compared with the delayed initiation of RRT [13]. These findings added further uncertainty about the efficacy of "early" RRT in critically ill patients. Despite numerous lowquality studies in this field, a definitive conclusion is still yet to be elucidated. Therefore, we aimed to conduct an updated systematic review and meta-analysis to evaluate the efficacy and safety of "early" initiation of RRT compared to "late" RRT in critically ill patients by collecting data from RCTs only because these represent the highest standard of evidence to support the optimal timing of RRT initiation.

\section{Methods}

\section{Search strategy}

We screened PubMed, EMBASE and Cochrane databases between January 1, 1985, and June 30, 2016, to identify randomized trials that assessed the timing of initiation of RRT in patients with AKI. The search strategies were restricted to human RCTs and English language. Studies published before 1985 were excluded because there has been great progress in RRT technology and critical care practices in recent years.

The following keywords or medical subject headings were used: "acute kidney injury", "acute kidney", "acute renal", "renal replacement therapy", "renal replacement", "hemodialysis", "hemofiltration", "dialysis", "dialyzed", "dialyzing", "time to treatment", "time", "timing", "initiation", "start", "accelerate", "accelerated", "accelerating", "acceleration", "early", "earlier", "late". The search was slightly adjusted according to the requirements of the different databases. The authors' personal files and reference lists of relevant review articles were also reviewed. The flow chart of the search strategies is summarized in Fig. 1.

\section{Study selection}

Studies reporting the timing of RRT initiation in patients with AKI were selected for further review. The inclusion criteria were as follows: (1) randomized controlled trials; (2) adult critically ill population; and (3) clearly comparing early versus late RRT initiation with effect on mortality and/or clinically relevant secondary outcomes. We excluded studies without clear comparisons of the outcomes. A cursory review of titles and abstracts was independently performed by two reviewers (Xiao-mei Yang and Guo-wei $\mathrm{Tu}$ ). Disagreement on the inclusion/exclusion of RCTs was resolved through consensus and, if necessary, consultation with a senior investigator (Zhe Luo). Retained RCTs were reviewed in detail.

\section{Data extraction}

Data extracted included basic characteristics (author's name, publication year, country of study, study period, study design, patient population, duration of follow-up, total number of patients, mean age, percentage of male), definition of "early" and "late" RRT, main characteristics at the time of RRT initiation (modality, creatinine, urine output, acute physiology and chronic health evaluation [APACHE II] score, sequential organ failure assessment [SOFA] score). The primary outcome was mortality, including 14-day mortality, 28-day mortality, 30-day mortality, 60-day mortality, 90-day mortality, ICU mortality, and in-hospital mortality. The longest follow-up mortality reported in the individual studies was extracted for the pooling analysis. Secondary outcomes included the ICU length of stay (LOS), hospital LOS, recovery of renal function, RRT dependence, duration of RRT, renal recovery time and mechanical ventilation time.

\section{Assessment of evidence quality}

The quality of evidence of each study was assessed (Xiaomei Yang and Jian Gao) according to the guidelines of the GRADE Working Group (http://www.gradeworkinggroup.org/index.html), using the GRADE profiler (version 3.6.1, http://ims.cochrane.org/revman/gradepro) and GRADE handbook to determine the quality of evidence and strength of recommendation.

\section{Statistical analysis}

Meta-analysis was performed using the relative risks (RRs) for binary outcome and weighted mean difference (WMD) for continuous outcome measures. Alternatively, when there was no event in either groups during the follow-up, we used relative difference (RD), defined as the difference in the incidence rate of the early RRT group from that in the late RRT group. Data were pooled using a random effects model based on the inverse variance approach to give a more conservative estimate of the effect, allowing for any heterogeneity between studies. Statistical heterogeneity among studies was assessed by using the Q statistic and $\mathrm{I}^{2}$ statistics [14]. Meta-analyses were performed using RevMan 5.3 (Cochrane IMS, Oxford, UK, http://ims.cochrane.org/revman/download). All additional analyses were performed by using Stata/MP 12.1 (Stata 


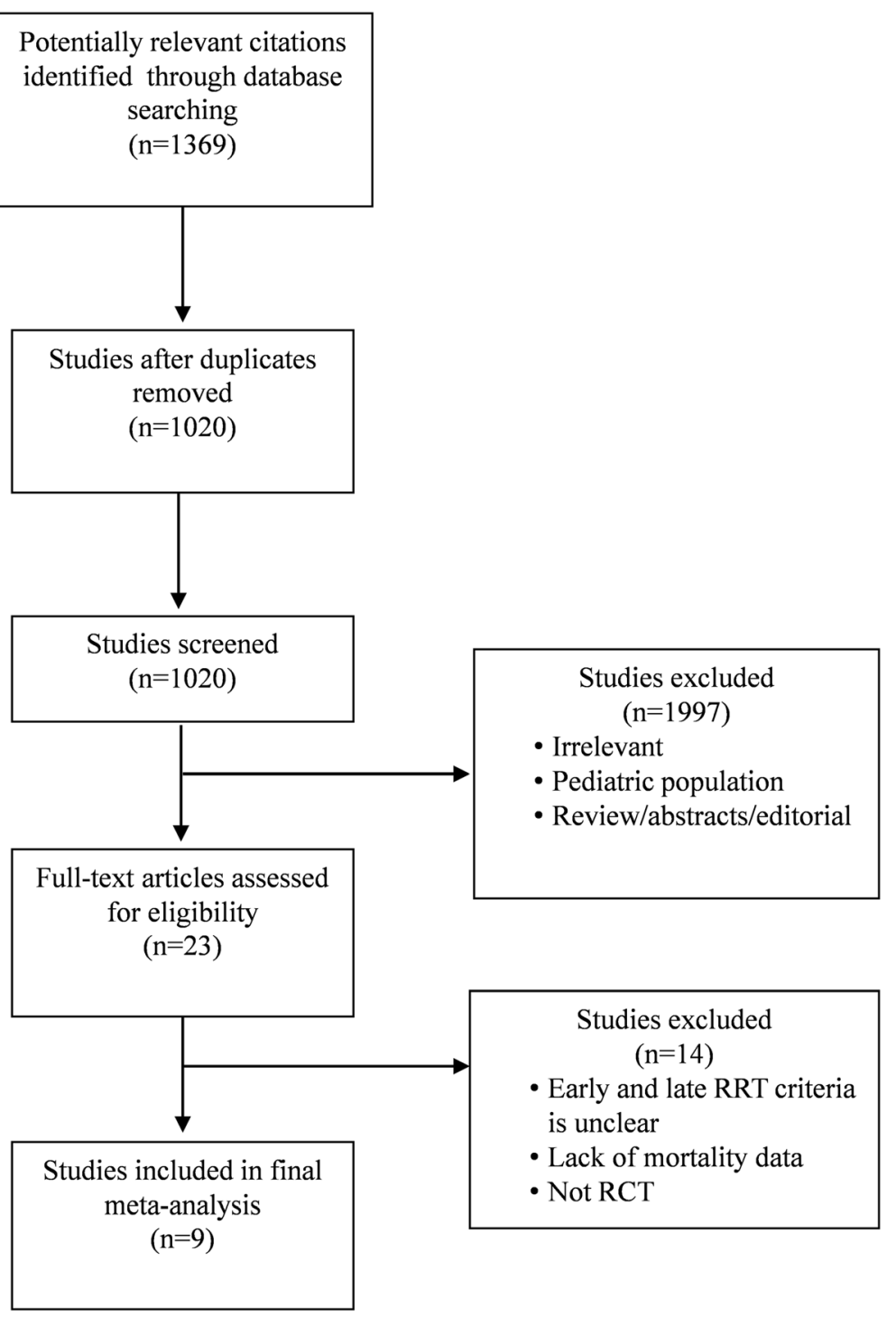

Fig. 1 Flow chart of literature selection

Corp, College Station, TX, USA). A $P$-value $<0.05$ was set as the threshold of statistical significance. Neither ethics board approval nor patient consent was required due to the nature of a systematic review.

Sensitivity analyses were conducted by excluding or subgrouping studies to reduce the potential confounding effects of patient population, RRT modality, study design, study sample size, duration of follow-up, urine output and creatinine. The log of the estimate of the study effect was set as the dependent variable in a general linear model, and the I2 and $P$-value were recalculated. Differences in the slopes of the linear regression models for the original and subgrouped data were used to predict the contributions of these potential confounding factors to the measured outcomes.

Risk of bias was assessed independently by 2 reviewers (Xiao-mei Yang and Guo-wei Tu) as recommended in the Cochrane Handbook, which includes 6 domains: selection bias, performance bias, detection bias, attrition bias, reporting bias, and other potential sources of bias. When there was insufficient information to allocate a high or low score, an "unclear" risk score was allocated. Disagreements in score allocations were resolved through group discussion. Publication bias was assessed using funnel plots, Begg's test and Egger's test [15], with $P<0.1$ indicative of reporting biases.

\section{Results}

Study selection

A total of 1020 potentially relevant citations were identified and screened from databases. We retrieved 23 articles for full-text review, and 14 were excluded based on 


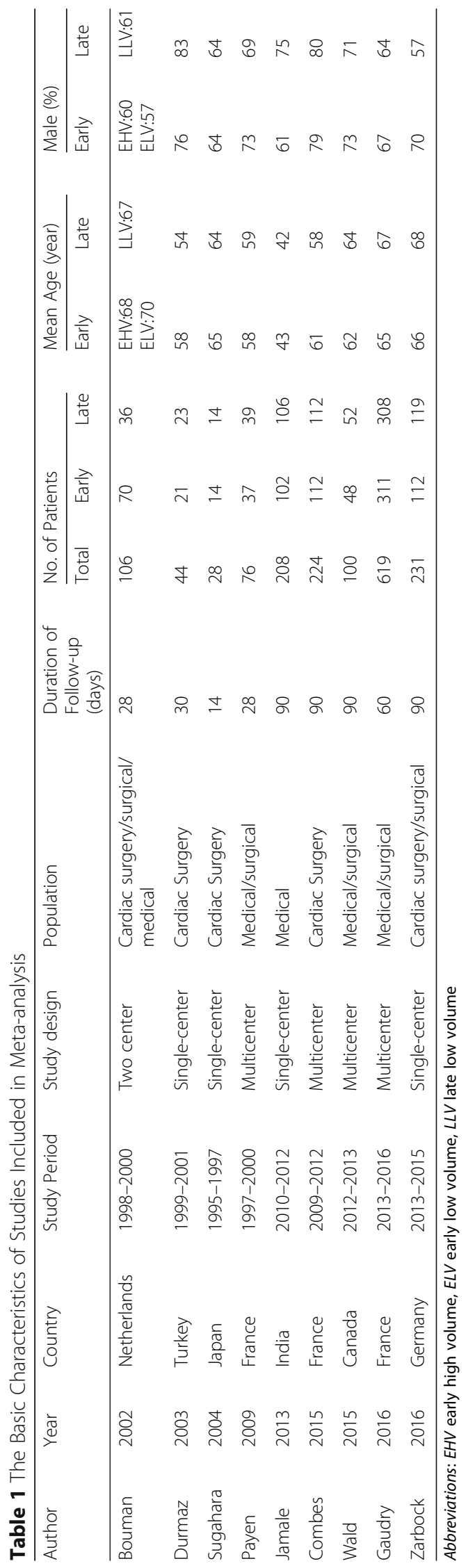


Table 2 Definition of Early and Late RRT in Studies Included in the Meta-analysis

\begin{tabular}{|c|c|c|c|}
\hline Author & Year & Early RRT Criteria & Late RRT Criteria \\
\hline Bouman & 2002 & $\begin{array}{l}\text { RRT within } 12 \mathrm{~h} \text { if urine output }<30 \mathrm{ml} / \mathrm{h}, \\
\mathrm{Cr} \text { clearance }<20 \mathrm{ml} / \mathrm{min} \text {, and mechanical } \\
\text { ventilation }\end{array}$ & Urea $>40 \mathrm{mmol} / \mathrm{L}$ or $\mathrm{K}>6.5 \mathrm{mmol} / \mathrm{L}$ or severe pulmonary edema \\
\hline Durmaz & 2003 & $\begin{array}{l}\text { Preoperative prophylactic RRT in all patients } \\
\text { and postoperative } \mathrm{sCr} \text { increased }>10 \%\end{array}$ & Postoperative sCr increased $>50 \%$ or urine output $<400 \mathrm{ml} / 24 \mathrm{~h}$ \\
\hline Sugahara & 2004 & $\begin{array}{l}\text { Urine output }<30 \mathrm{ml} / \mathrm{h} \text { for } 3 \mathrm{~h} \text { or urine } \\
\text { output }<750 \mathrm{ml} / \text { day }\end{array}$ & Urine output $<20 \mathrm{ml} / \mathrm{h}$ for $2 \mathrm{~h}$ or urine output $<500 \mathrm{ml} /$ day \\
\hline Payen & 2009 & $\begin{array}{l}\text { RRT for } 96-\mathrm{h} \text { period within } 24 \mathrm{~h} \text { of diagnosis } \\
\text { of severe sepsis }\end{array}$ & Classic indications for RRT \\
\hline Jamale & 2013 & $\begin{array}{l}\text { Serum urea nitrogen }>70 \mathrm{mg} / \mathrm{dL} \text { and/or } \\
\text { creatinine }>7 \mathrm{mg} / \mathrm{dL}\end{array}$ & Classic indications for RRT or Uremic nausea and anorexia \\
\hline Combes & 2015 & $\begin{array}{l}\text { RRT within } 24 \mathrm{~h} \text { of diagnosis of post-cardiac } \\
\text { surgery shock }\end{array}$ & $\begin{array}{l}\text { Creatinine }>4 \mathrm{mg} / \mathrm{dL} \text { or preoperative creatinine } \times 3 \text { or urine } \\
\text { output }<0.3 \mathrm{ml} / \mathrm{kg} / \mathrm{h} / 24 \text { h or urea }>36 \mathrm{mmol} / \mathrm{L} \text { or life-threatening } \\
\text { hyperkalemia }\end{array}$ \\
\hline Wald & 2015 & $\begin{array}{l}\text { sCr increased }>200 \% \text {, urine output }<6 \mathrm{ml} / \mathrm{kg} \\
\text { within } 12 \mathrm{~h} \text {, or NGAL } \geq 400 \mathrm{ng} / \mathrm{ml}\end{array}$ & $\begin{array}{l}\mathrm{K}>6.0 \mathrm{mmol} / \mathrm{L} \text { or serum bicarbonate }<10 \mathrm{mmol} / \mathrm{L} \text { or pulmonary } \\
\text { edema }\end{array}$ \\
\hline Gaudry & 2016 & RRT within $6 \mathrm{~h}$ of diagnosis of KDIGO stage 3 & $\begin{array}{l}\mathrm{K}>6.0 \mathrm{mmol} / \mathrm{L} \text { or } \mathrm{PH}<7.15 \text { or pulmonary edema or blood urea } \\
\text { nitrogen }>112 \mathrm{mg} / \mathrm{dL} \text { or oliguria }>72 \mathrm{~h}\end{array}$ \\
\hline Zarbock & 2016 & RRT within $8 \mathrm{~h}$ of diagnosis of KDIGO stage 2 & RRT within 12 h of KDIGO stage 3 or no RRT \\
\hline
\end{tabular}

Abbreviations: $R R T$ renal replacement therapy, $\mathrm{Cr}$ creatinine, $s \mathrm{Cr}$ serum creatinine, $K$ potassium, $K D I G O$ kidney disease: improving global outcomes, $N G A L$ neutrophil gelatinase-associated lipocalin

eligibility criteria. Nine RCTs fulfilled all criteria for the final meta-analysis (Fig. 1). All studies were written in English.

\section{Characteristics of the studies}

The basic characteristics of the studies selected are shown in Table 1. A total of 1636 patients were enrolled. Of these studies, four of the studies were multi-center studies [12, 16-18], four were single-center studies [13, 19-21], and one was a two-center study [22]. Three studies examined only patients following cardiac surgery $[17,19,20]$, whereas the remaining six studies were mixed with medical or surgical patients $[12,13,16,18,21,22]$. The follow-up time reported in these studies ranged from 14 to 90 days.

The definition of early and late initiation of RRT for each specific study is outlined in Table 2. Five studies used urine output and/or serum creatinine or serum urea nitrogen or creatinine clearance for defining early and late RRT [18-22], two studies started early RRT when with diagnosis of severe sepsis or post-cardiac surgery shock [16, 17], and the latest two studies in 2016 used Kidney Disease: Improving Global Outcomes (KIDGO) stage 2 or stage 3 to define early RRT $[12,13]$. In most of the studies, late RRT was defined as a classic

Table 3 The Characteristics at the time of renal replacement therapy initiation in studies included in Meta-analysis

\begin{tabular}{|c|c|c|c|c|c|c|c|c|c|}
\hline \multirow[t]{2}{*}{ Author } & \multirow[t]{2}{*}{ Modality } & \multicolumn{2}{|c|}{ Creatinine (mg/d L) } & \multicolumn{2}{|c|}{ Urine output (ml/24 h) } & \multicolumn{2}{|c|}{ APACHE II score } & \multicolumn{2}{|l|}{ SOFA score } \\
\hline & & Early & Late & Early & Late & Early & Late & Early & Late \\
\hline Bouman & $\mathrm{CWH}$ & $N R$ & $N R$ & NR & NR & $\begin{array}{l}\text { EHV:23.5 (8.4) } \\
\text { ELV:21.7 (5.5) }\end{array}$ & LLV:23.6 (8.3) & $\begin{array}{l}\text { EHV:10.3 (2.8) } \\
\text { ELV:10.1 (2.2) }\end{array}$ & LLV:10.6 (1.9) \\
\hline Durmaz & $\mathrm{IHD}$ & $3.1(1.0)$ & $4.3(1.1)$ & NR & $N R$ & $N R$ & $N R$ & $N R$ & $N R$ \\
\hline Sugahara & $\mathrm{CWH}$ & $2.9(0.2)$ & $3.0(0.2)$ & $29(1)^{a}$ & $18(1)^{\mathrm{a}}$ & $19(2)$ & $18(3)$ & NR & NR \\
\hline Payen & $\mathrm{CWH}$ & $2.1(1.1)$ & $2.1(1.3)$ & $1543(209)$ & $1491(242)$ & $N R$ & NR & NR & NR \\
\hline Jamale & $\mathrm{HD}$ & $7.4(5.3)$ & $10.4(3.3)$ & $429(388)$ & $376(350)$ & $N R$ & $N R$ & $7.6(3.3)$ & $8.2(3.1)$ \\
\hline Combes & $\mathrm{CWH}$ & $1.7(0.9)$ & $1.8(0.9)$ & $N R$ & $N R$ & $N R$ & NR & $11.5(2.8)$ & $12(2.9)$ \\
\hline Wald & IHD/CWH/SLED & $3.7(1.4)$ & $4.6(2.2)$ & $400(211-568)$ & $265(80-755)$ & $N R$ & $N R$ & $12(3.3)$ & $11.9(2)$ \\
\hline Gaudry & $\mathrm{HD} / \mathrm{CWH}$ & $3.3(1.4)$ & $5.3(2.3)$ & $N R$ & $150(50-600)$ & $N R$ & $N R$ & $10.9(3.2)$ & $10.8(3.1)$ \\
\hline Zarbock & $\mathrm{CWH}$ & $1.9(0.6)$ & $2.4(1)$ & $445(175-807.5)$ & $270(112.5-670)$ & $30.6(7.5)$ & $32.7(8.8)$ & $15.6(2.3)$ & $16(2.3)$ \\
\hline
\end{tabular}

Abbreviations: NR not reported, APACHE acute physiology and chronic health evaluation, SOFA sequential organ failure assessment, EHV early high volume, ELV early low volume, LLV late low volume, CVVH continuous venovenous hemofiltration, IHD intermittent hemodialysis, SLED sustained low-efficiency dialysis

${ }^{a}$ Sugahar reported urine output by $\mathrm{ml} / \mathrm{h}$ 


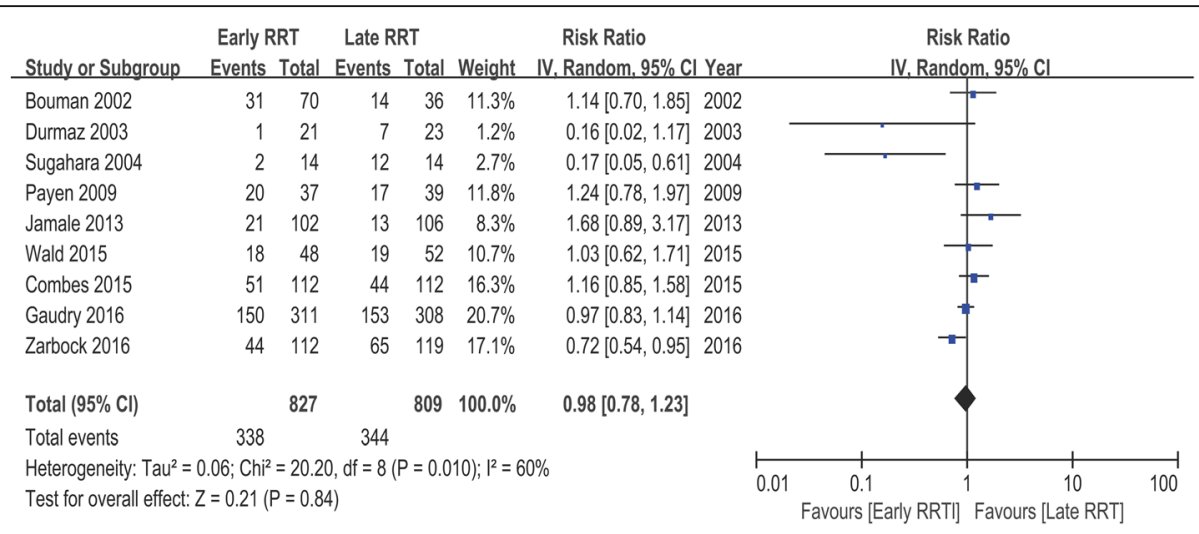

Fig. 2 Forest plot for mortality of 9 studies

Table 4 Subgroup Meta-analyses and Meta regression Analyses

\begin{tabular}{|c|c|c|c|c|c|c|c|}
\hline Subgroup & No. of Studies & No. of Patients & $\begin{array}{l}\text { Random-Effects Model } \\
\text { RR ( } 95 \% \text { Cl) }\end{array}$ & Test for Effect $P$ & $\mathrm{I}^{2}(\%)$ & Test for Heterogeneity $P$ & Meta regression $P$ \\
\hline All Studies & 9 & 1636 & $0.98(0.78,1.23)$ & 0.84 & 60 & 0.01 & \\
\hline Study Design & & & & & & & 0.216 \\
\hline Single-center & 4 & 511 & $0.58(0.25,1.36)$ & 0.21 & 78 & 0.003 & \\
\hline Multicenter & 5 & 1125 & $1.03(0.91,1.17)$ & 0.61 & 0 & 0.75 & \\
\hline Sample Size & & & & & & & 0.362 \\
\hline$<100$ & 3 & 148 & $0.37(0.07,1.90)$ & 0.23 & 82 & 0.004 & \\
\hline$\geq 100$ & 6 & 1488 & $1.00(0.83,1.21)$ & 0.98 & 44 & 0.11 & \\
\hline \multicolumn{8}{|l|}{ Patient Population } \\
\hline Multisystem & 6 & 1340 & $1.00(0.82,1.22)$ & 0.99 & 42 & 0.120 & \\
\hline Post cardiac surgery & 3 & 296 & $0.37(0.07,1.81)$ & 0.22 & 83 & 0.003 & \\
\hline RRT Modality & & & & & & & 0.838 \\
\hline $\mathrm{CWH}$ & 5 & 665 & $0.91(0.63,1.32)$ & 0.62 & 71 & 0.007 & \\
\hline $\mathrm{HD}$ & 2 & 252 & $0.63(0.06,6.19)$ & 0.69 & 79 & 0.03 & \\
\hline $\mathrm{CWH} / \mathrm{IHD}$ & 2 & 719 & $0.98(0.84,1.14)$ & 0.75 & 0 & 0.84 & \\
\hline Days of Follow up & & & & & & & 0.681 \\
\hline$<60$ & 4 & 254 & $0.65(0.30,1.43)$ & 0.29 & 74 & 0.009 & \\
\hline$\geq 60$ & 5 & 1382 & $0.99(0.80,1.23)$ & 0.95 & 53 & 0.07 & \\
\hline Creatinine Difference & & & & & & & 0.632 \\
\hline Significant & 4 & 583 & $0.92(0.55,1.53)$ & 0.74 & 67 & 0.03 & \\
\hline Nonsignificant & 5 & 1053 & $1.02(0.78,1.33)$ & 0.87 & 57 & 0.05 & \\
\hline UO Difference & & & & & & & 0.079 \\
\hline Significant & 2 & 259 & $0.40(0.10,1.63)$ & 0.20 & 78 & 0.03 & \\
\hline Nonsignificant & 5 & 1227 & $1.05(0.92,1.19)$ & 0.48 & 0 & 0.42 & \\
\hline KDIGO & & & & & & & 0.334 \\
\hline stage $1-2$ & 5 & 627 & $0.74(0.47,1.17)$ & 0.20 & 72 & 0.01 & \\
\hline stage 3 & 3 & 933 & $1.08(0.84,1.40)$ & 0.54 & 31 & 0.23 & \\
\hline
\end{tabular}




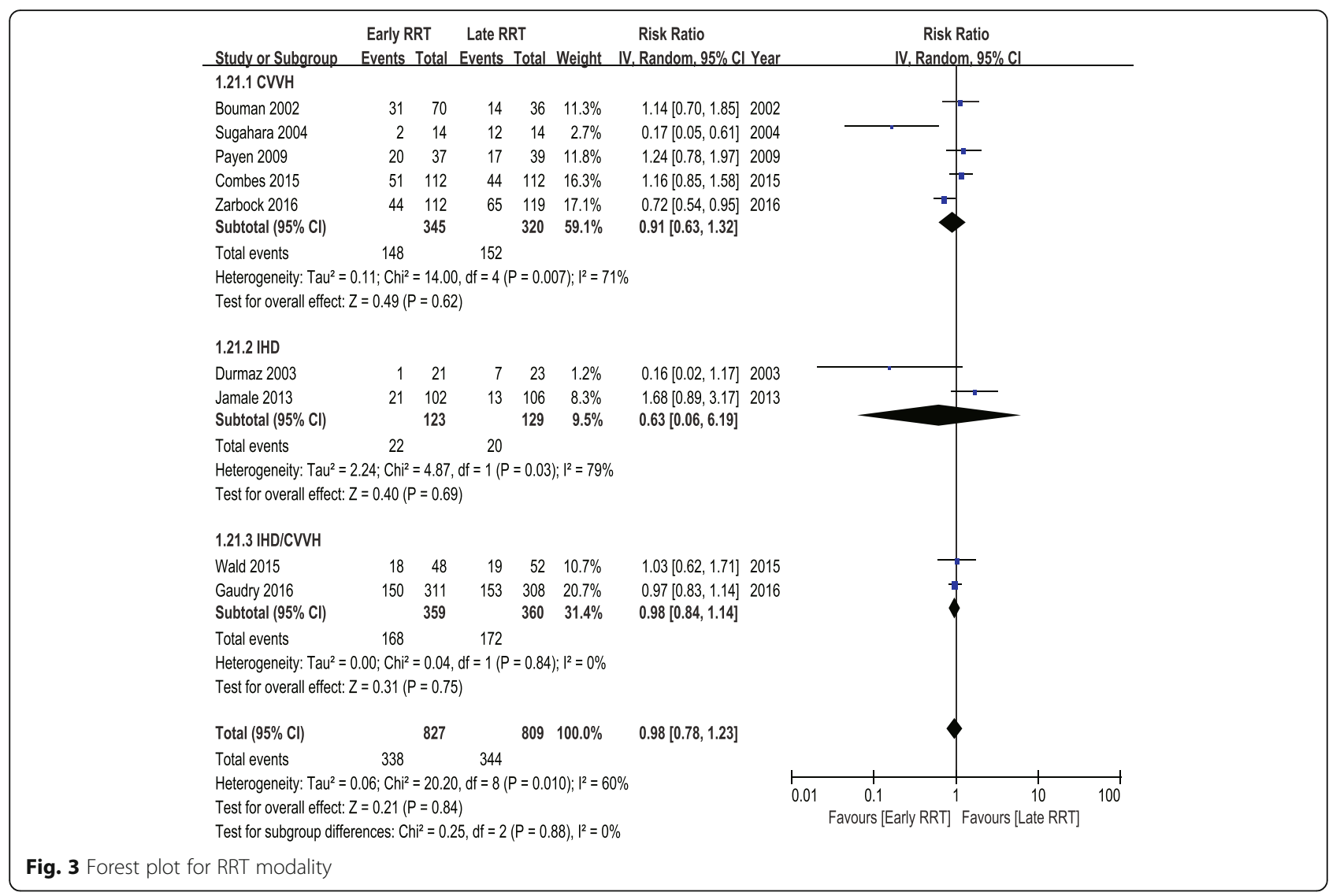

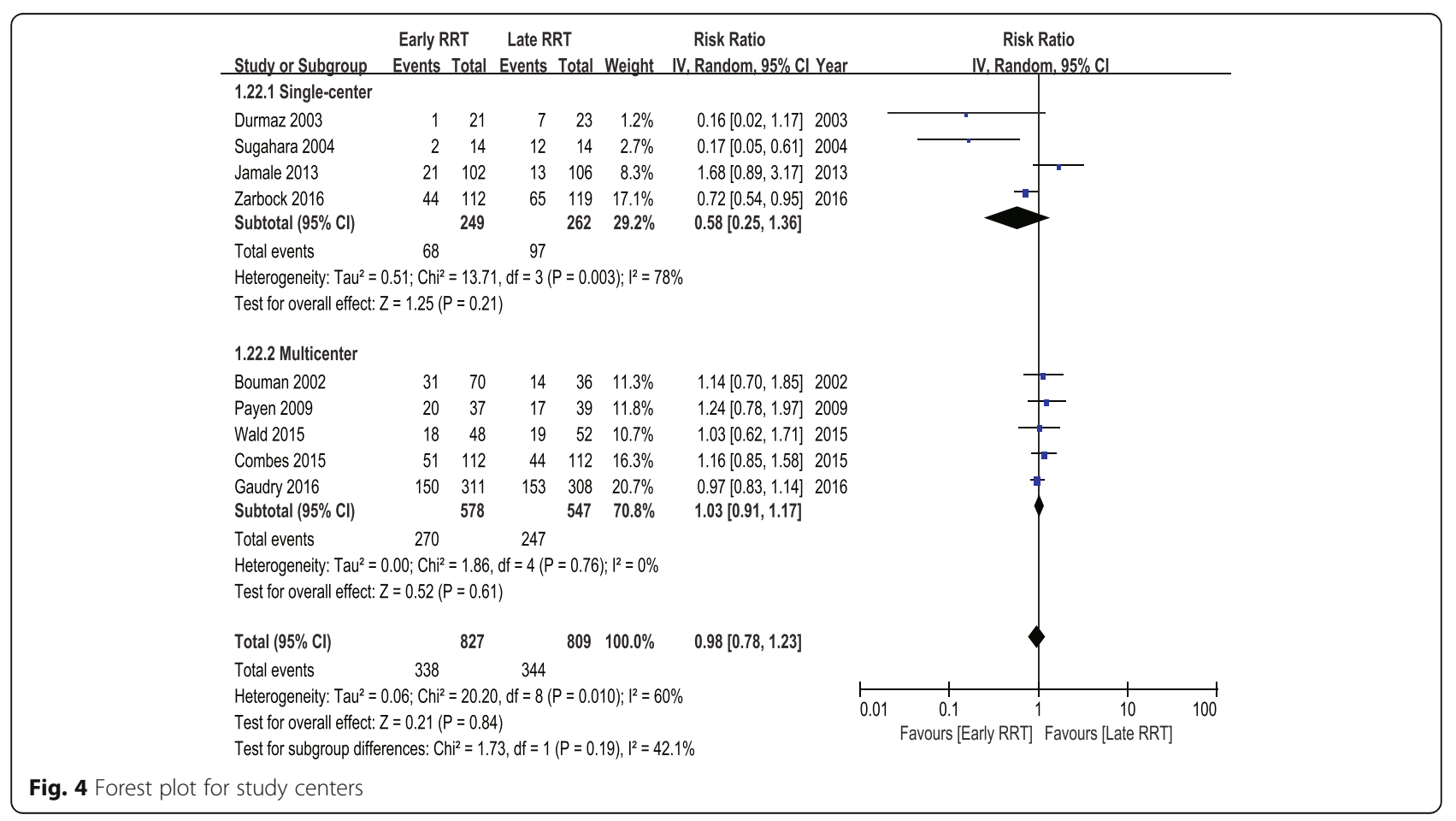




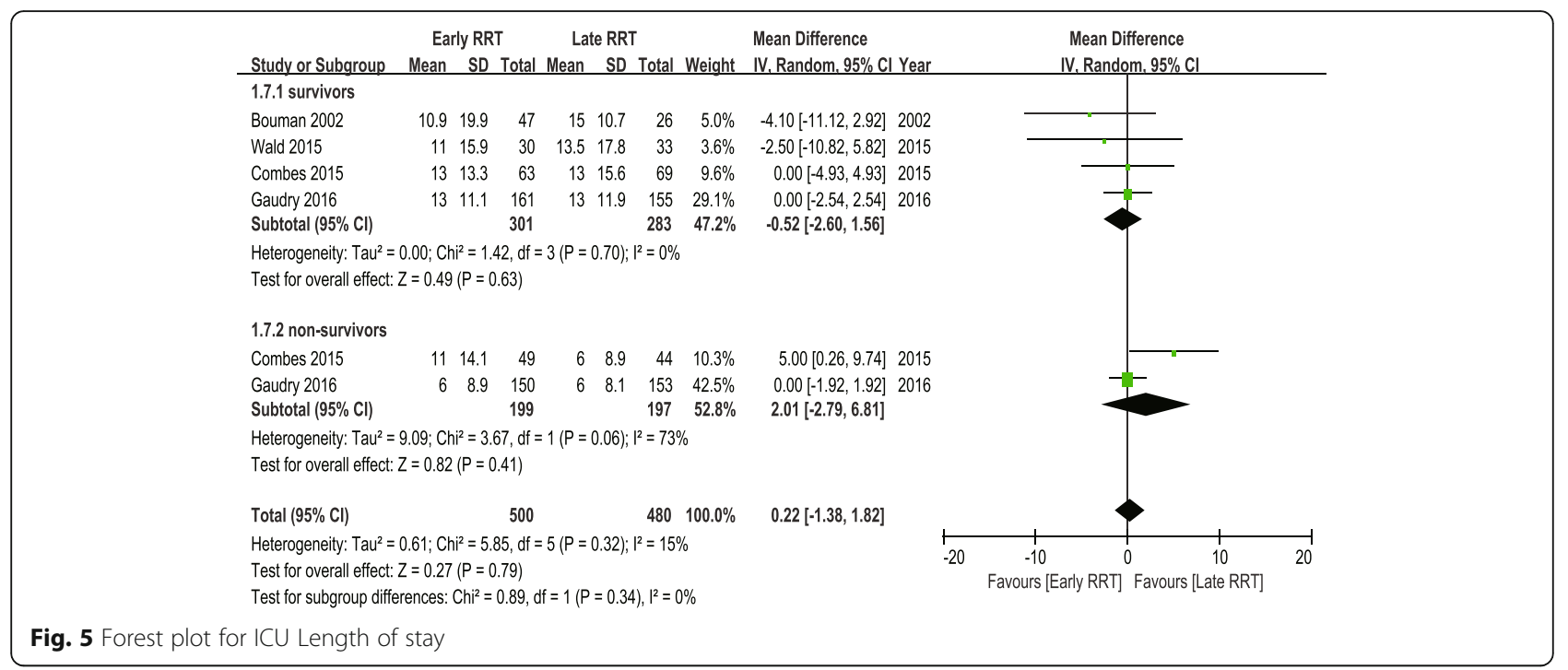

indication, including azotemia, oliguria, pulmonary edema, hyperkalemia and metabolic acidosis. The individual studies defined early and late RRT by using variable cutoff values in serum creatinine or urine output.

The modality of RRT varied significantly among the individual studies (Table 3 ). The modality of continuous vena-venous hemofiltration $(\mathrm{CVVH})$ was used in five studies [13, 16, 17, 20, 22] and intermittent hemodialysis (IHD) was used in two studies $[19,21]$. In the remaining two studies, some of the patients received CVVH modality, and the others received IHD or sustained low-efficiency dialysis (SLED) modality $[12,18]$. At the time of initiation of RRT, the early group had serum creatinine ranging from 1.7 to $7.4 \mathrm{mg} / \mathrm{dL}$ and urine output from 400 to $1543 \mathrm{ml} /$ day while the late group had serum creatinine ranging from 1.8 to $10.4 \mathrm{mg} / \mathrm{dL}$ and urine output ranging from 150 to
$1491 \mathrm{ml} /$ day (Table 3). Several studies reported illness severity measured by APACHE II score and SOFA score before RRT initiation. The APACHE II score ranged from 19 to 30.6 in the early group and 18 to 32.7 in the late group, whereas the SOFA score ranged from 7.6 to 15.6 in the early group and 8.2 to 16 in the late group (Table 3).

\section{Primary outcome}

The definition of mortality reported in these studies differed considerably, including 14-day mortality [20], 28 -day mortality $[12,13,16,22]$, 30-day mortality [17], 60-day mortality [12, 13, 17], 90-day mortality $[13,17,18]$, ICU mortality $[17,18,22]$, and inhospital mortality $[17-19,21,22]$. We selected the longest follow-up mortality of each study as the primary end point. Figure 2 showed the mortalities of

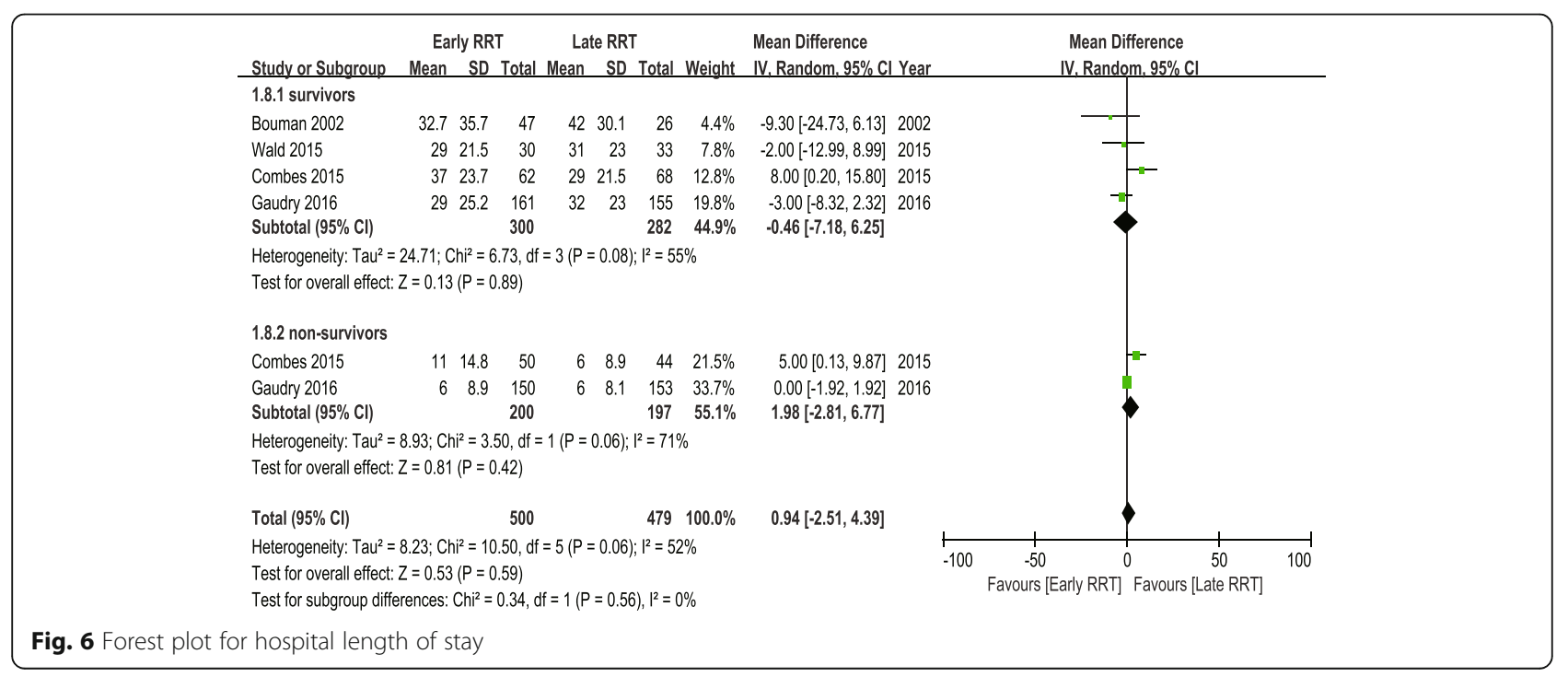




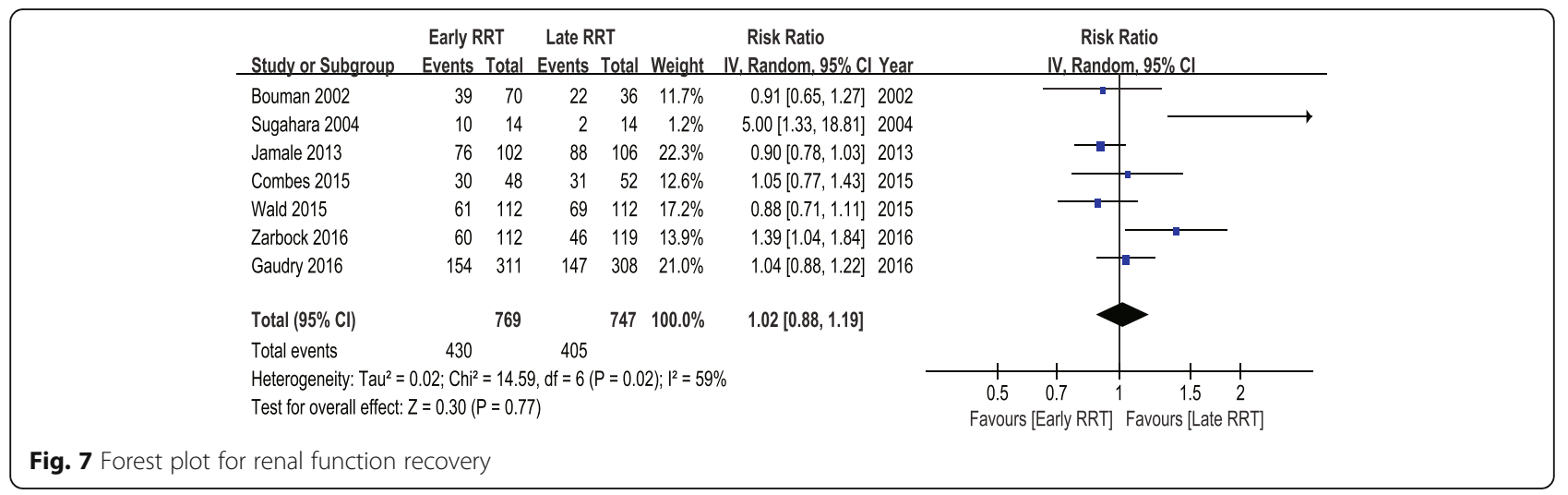

individual studies and pooled analysis. The total number of participants was 827 in the early group, with 338 deaths, and 809 in the late group, with 344 deaths. Pooled analysis of the studies indicated no mortality benefit with "early" RRT, with an RR of 0.98 (95\% CI 0.78 to 1.23, $P=0.84)$. However, there was relatively high statistical heterogeneity with an $\mathrm{I}^{2}$ value of $60 \%(P=0.01)$.

\section{Subgroup analysis}

To explore the factors that may result in heterogeneity, several subgroup analyses were performed. Analyses grouped by patient population (post cardiac surgery versus multisystem), by RRT modality (CVVH versus IHD or IHD/CVVH), by study design (single center versus multicenter), by study sample size $(\geq 100$ versus $<100)$, by duration of follow-up ( $\geq 100$ days versus $<100$ days), by urine output (significant difference versus no significant difference between early and late RRT group), by creatinine (significant difference versus no significant difference between early and late RRT group), or by KDIGO classification of early RRT group (stage 12 versus stage 3 ) demonstrated no significant difference in the overall effect estimates. Meta-regression analyses showed no statistically significant association between RR and patient population, RRT modality, study design, study sample size, duration of follow-up, urine output, creatinine, and KDIGO classification (Table 4, Figs. 3 and 4).

\section{Secondary outcomes}

The analysis of secondary outcomes included the ICU LOS, hospital LOS, recovery of renal function, RRT dependence, duration of RRT, renal recovery time and mechanical ventilation time. Due to the variability in the reporting of ICU LOS and hospital LOS, we performed a pooled analysis for subgroups, including ICU LOS/hospital LOS in survivors and nonsurvivors. There was no significant difference in ICU LOS and heterogeneity between early and late RRT group for survivors or nonsurvivors (Fig. 5). A similar subgroup analysis performed on hospital LOS also showed no significant difference (Fig. 6). Seven of the nine studies reported recovery of renal function and RRT dependence. Pooled analysis also demonstrated no significant change in renal function recovery (RR $1.02,95 \%$ CI 0.88 to $1.19, \mathrm{I}^{2}=59 \%$; Fig. 7 ) or RRT dependence (RR 0.76 , 95\% CI 0.42 to 1.37, $\mathrm{I}^{2}=0 \%$; Fig. 8) between the early and late RRT groups. Three studies reported the duration of RRT [13, 17, 21], two studies reported renal recovery time [21, 22] and three studies reported mechanical ventilation time [13, 17, 22]. Pooled analysis of these studies showed no significant increase in duration of RRT in early RRT (Mean difference

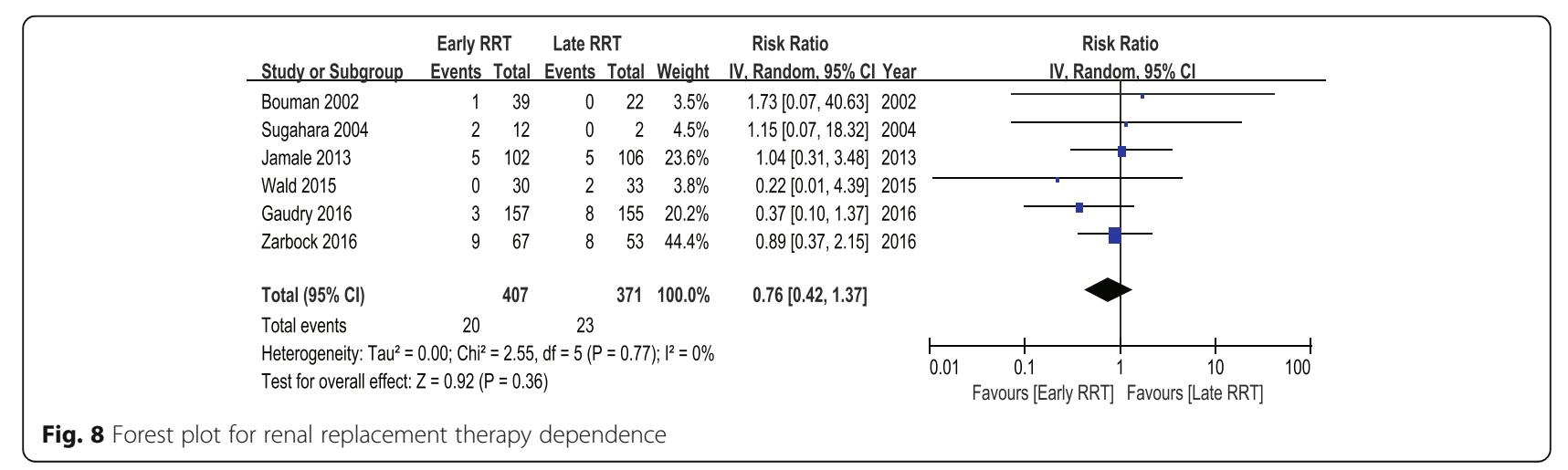




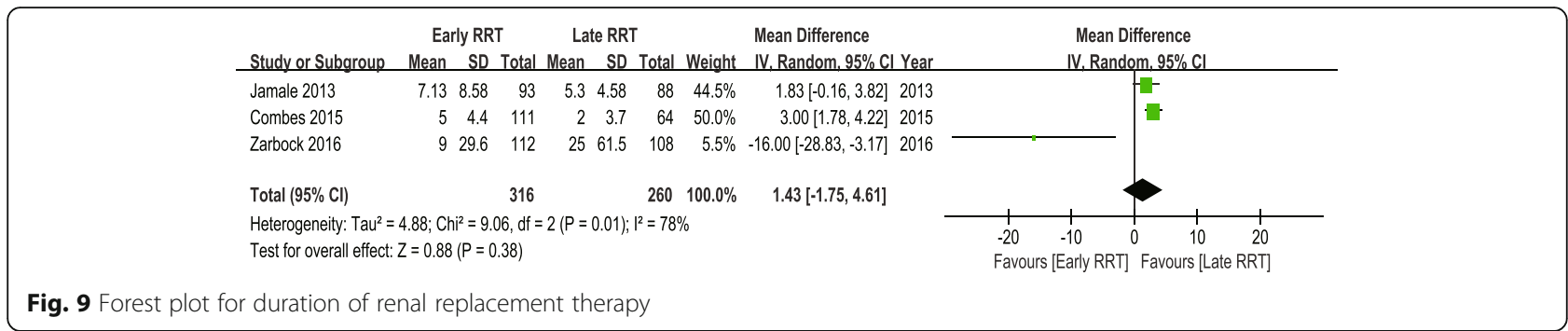

1.43, $95 \%$ CI -1.75 to $4.61, \mathrm{I}^{2}=78 \%$; Fig. 9), renal recovery time (Mean difference $0.73,95 \%$ CI -2.09 to $3.56, \mathrm{I}^{2}=70 \%$; Fig. 10) or mechanical ventilation time (Mean difference $-0.95,95 \%$ CI -3.54 to $1.64, \mathrm{I}^{2}=64 \%$; Fig. 11 ).

\section{Assessment of evidence quality}

One critical outcome (the overall mortality of patients) and 7 important outcomes, including ICU LOS of survivors, hospital LOS of survivors, renal function recovery, renal recovery time, duration of RRT, RRT dependence and mechanical ventilation time, were evaluated using the GRADE system. The level of evidence quality was moderate for overall mortality and low for other secondary outcomes (Table 5).

\section{RRT-related complications}

Several RRT-related complications were reported in the studies, including hemorrhage, thrombocytopenia, thrombosis, hypokalemia, hypophosphatemia, hyperkalemia, RRTassociated arrhythmia, RRT-associated seizure, hypothermia, catheter infection and hypotension during RRT (Table 6). We found no significant differences in complications between the early and late RRT groups, with no heterogeneity between trials, except for hypophosphatemia $\left(\mathrm{I}^{2}=92 \%\right.$; $P<0.0001)$.

\section{Risk of bias and publication bias}

Risk of bias is shown in Fig. 12. Of the nine studies, two studies did not report random sequence generation, and three studies did not report allocation concealment and were thus considered to have an unclear risk of bias. Overall, the included RCTs had a low risk of bias. The funnel plot was symmetrical (Fig. 13), which indicated the absence of publication bias between the trials included in our meta-analysis $(P=0.832$, Egger's test; $P=0.917$, Begg's test).

\section{Discussion}

Although the need to initiate RRT is unequivocal in AKI patients with traditional indications, the advantages of commencing RRT in the absence of life-threatening complications are still under controversial [18]. Despite numerous low-quality studies in this field, the definitive conclusion is still yet to be elucidated. There is insufficient evidence to suggest that early initiation of RRT is related to reduced mortality or other patient-centered outcomes in critically ill patients. It should be mentioned that the spontaneous recovery of renal function may occur in certain patients with AKI. In the AKIKI study, up to $49 \%$ of the patients in the delayed-strategy group avoided receiving RRT [12]. However, we cannot accurately predict the needs for RRT or opportunity of renal recovery in critically ill patients in the retrospective studies. One may even argue that patients in the early RRT group might have less severe conditions or more opportunity to have a spontaneous recovery of renal function, both of which might account for the improved outcomes. Therefore, the optimal timing of initiation of RRT cannot be accurately gained from retrospective studies. Four meta-analyses indicated that "early" initiation of RRT might reduce the mortality of patients with AKI compared with "late" RRT, but most of the enrolled trials were retrospective cohort studies which could affect the facticity of the final conclusion [9, 11, 23, 24].

We enrolled 9 RCTs with a total of 1636 patients in this meta-analysis and found that "early" RRT had no beneficial effect on mortality of patients with AKI compared with "late" RRT. Furthermore, pooled analysis of these studies also showed no significant benefit of early RRT in renal

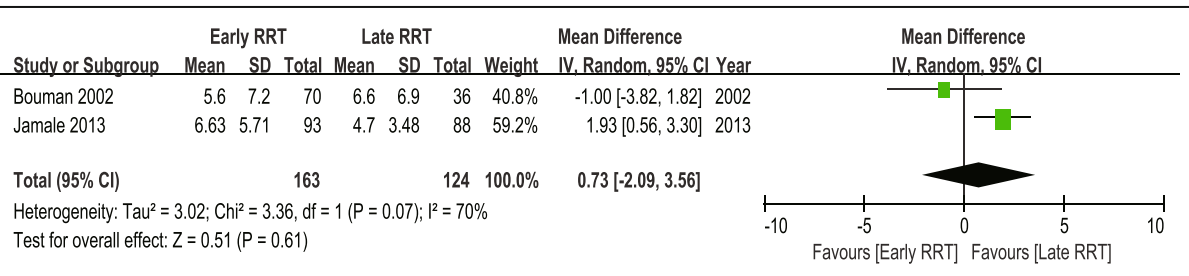

Fig. 10 Forest plot for renal recovery time 


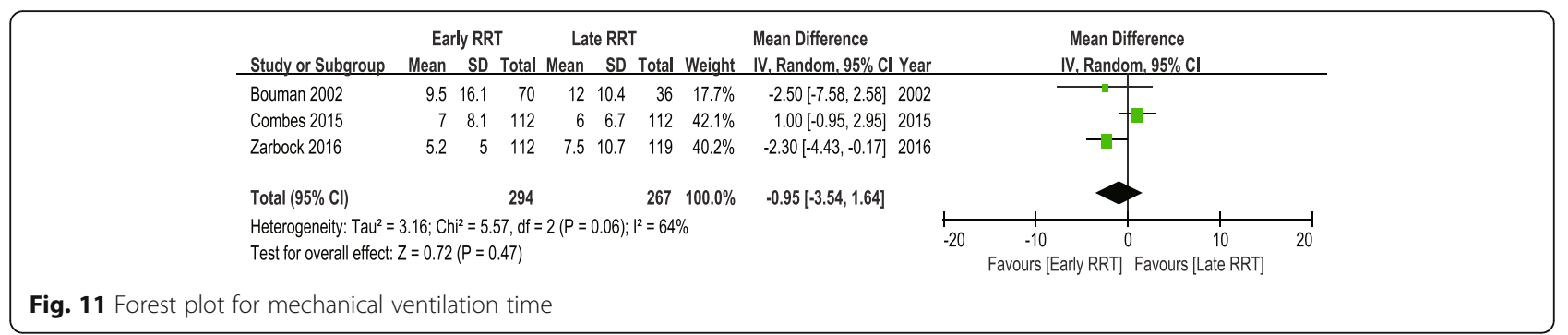

function recovery, renal recovery time, RRT dependence, duration of RRT or mechanical ventilation time. It has been known that there are many differences between postcardiac surgery patients and those with noncardiac surgery, especially on the perioperative hemodynamic management. However, subgroup analysis of the studies concerning the patients post cardiac surgery or those with noncardiac surgery did not reveal a survival benefit of early RRT intervention. In addition, the conclusion remained the same, regardless of whether early was defined by AKI stages according to the KDIGO classification or on the basis of urine output or serum creatinine.

One highlight of this meta-analysis was that we included two new large RCTs published recently [12, 13], which made our results more convincing. Second, RRT-related complications were evaluated in the meta-analysis, and no significant differences in complications between the early and late RRT groups were found. Third, survivors and nonsurvivors were analyzed separately in the secondary outcome analysis, and the same conclusion was reached. Fourth, this meta-analysis was performed under the requirements of Preferred Reporting Items for Systematic reviews and Meta-Analyses (PRISMA), which enhances the reliability of the conclusion. The quality of evidence and strength of recommendations were rated according to the guidelines of the GRADE Working Group.

However, facing the results we got, we could not confirm the conclusion definitively. There was relatively high heterogeneity with an $\mathrm{I}^{2}$ value of $60 \%$, which might be explained by the significant variation in study design, population characteristics, baseline AKI severity, initiation time of RRT, modality used, and duration of follow-up among studies. The most fundamental differences among the trials were the huge differences concerning the timing

Table 5 Rating the Quality of Evidences by GRADE

\begin{tabular}{|c|c|c|c|c|c|c|c|c|}
\hline \multirow[t]{2}{*}{ Outcomes } & \multirow[t]{2}{*}{ Studies } & \multicolumn{2}{|c|}{ No. of Participants } & \multicolumn{2}{|l|}{$\underline{\text { Effect }}$} & \multirow[t]{2}{*}{ Quality } & \multirow[t]{2}{*}{ Importance } & \multirow{2}{*}{$\begin{array}{l}\text { Recommendation } \\
\text { grade }\end{array}$} \\
\hline & & Early RRT & Late RRT & $\mathrm{RR} / \mathrm{RD}(95 \% \mathrm{Cl})$ & Absolute & & & \\
\hline Overall mortality & 9 & $\begin{array}{l}338 / 827 \\
(40.9 \%)\end{array}$ & $\begin{array}{l}344 / 809 \\
(42.5 \%)\end{array}$ & $\begin{array}{l}\text { RR } 0.98 \\
\text { (0.78 to } 1.23 \text { ) }\end{array}$ & $\begin{array}{l}9 \text { fewer per } 1000 \\
\text { (from } 94 \text { fewer to } \\
98 \text { more) }\end{array}$ & $\begin{array}{l}\oplus \oplus \oplus O \\
\text { Moderate }\end{array}$ & Critical & Weak \\
\hline ICU LOS of survivors & 4 & 301 & 283 & - & $\begin{array}{l}\text { MD } 0.52 \text { lower } \\
\text { (2.6 lower to } \\
1.56 \text { higher) }\end{array}$ & $\begin{array}{l}\oplus \oplus \mathrm{OO} \\
\text { low }\end{array}$ & Important & Weak \\
\hline Hospital LOS of survivors & 4 & 300 & 282 & - & $\begin{array}{l}\text { MD } 0.46 \text { lower } \\
\text { ( } 7.18 \text { lower to } \\
6.25 \text { higher) }\end{array}$ & $\begin{array}{l}\oplus \oplus \mathrm{OO} \\
\text { low }\end{array}$ & Important & Weak \\
\hline Renal function recovery & 7 & $\begin{array}{l}430 / 769 \\
(55.9 \%)\end{array}$ & $\begin{array}{l}405 / 747 \\
(54.2 \%)\end{array}$ & $\begin{array}{l}\text { RR } 1.02 \\
\text { (0.88 to 1.19) }\end{array}$ & $\begin{array}{l}11 \text { more per } 1000 \\
\text { (from } 65 \text { fewer to } \\
103 \text { more) }\end{array}$ & $\begin{array}{l}\oplus \oplus \mathrm{OO} \\
\text { low }\end{array}$ & Important & Weak \\
\hline Renal recovery time & 2 & 163 & 124 & - & $\begin{array}{l}\text { MD } 0.73 \text { higher } \\
\text { ( } 2.09 \text { lower to } \\
3.56 \text { higher) }\end{array}$ & $\begin{array}{l}\oplus \oplus \mathrm{OO} \\
\text { low }\end{array}$ & Important & Weak \\
\hline Duration of RRT & 3 & 316 & 260 & - & $\begin{array}{l}\text { MD } 1.43 \text { higher } \\
\text { ( } 1.75 \text { lower to } \\
4.61 \text { higher) }\end{array}$ & $\begin{array}{l}\oplus \oplus \mathrm{OO} \\
\text { low }\end{array}$ & Important & Weak \\
\hline RRT dependence & 7 & $\begin{array}{l}19 / 447 \\
(4.3 \%)\end{array}$ & $\begin{array}{l}23 / 427 \\
(5.4 \%)\end{array}$ & $\begin{array}{l}\text { RR } 0.76 \\
\text { (0.42 to } 1.37)\end{array}$ & $\begin{array}{l}13 \text { fewer per } 1000 \\
\text { (from } 31 \text { fewer } \\
\text { to } 20 \text { more) }\end{array}$ & $\begin{array}{l}\oplus \oplus \mathrm{OO} \\
\text { low }\end{array}$ & Important & Weak \\
\hline Mechanical ventilation time & 3 & 294 & 267 & - & $\begin{array}{l}\text { MD } 0.95 \text { lower } \\
\text { (3.54 lower to } \\
\text { 1.64 higher) }\end{array}$ & $\begin{array}{l}\oplus \oplus \mathrm{OO} \\
\text { low }\end{array}$ & Important & Weak \\
\hline
\end{tabular}


Table 6 RRT-related Complications of Studies Included in Meta-analysis

\begin{tabular}{|c|c|c|c|c|c|c|}
\hline Outcomes & Study No. & No of patients & Risk Difference $(95 \% \mathrm{Cl})$ & $P$ for Effect & $1^{2}$ & $P$ for Model \\
\hline hemorrhage & 6 & 1458 & $0.00(-0.02,0.01)$ & 0.89 & $0 \%$ & 0.73 \\
\hline thrombocytopenia & 3 & 949 & $0.05(-0.04,0.14)$ & 0.25 & $60 \%$ & 0.08 \\
\hline thrombosis & 2 & 700 & $-0.01(-0.04,0.02)$ & 0.40 & $0 \%$ & 0.58 \\
\hline hypokalemia & 3 & 924 & $0.00(-0.08,0.07)$ & 0.89 & $61 \%$ & 0.08 \\
\hline hypophosphatemia & 3 & 924 & $0.11(-0.09,0.31)$ & 0.28 & $92 \%$ & $<0.0001$ \\
\hline hyperkalemia & 2 & 843 & $-0.01(-0.04,0.02)$ & 0.41 & $0 \%$ & 0.56 \\
\hline RRT-associated arrhythmia & 3 & 920 & $-0.02(-0.08,0.04)$ & 0.48 & $58 \%$ & 0.09 \\
\hline RRT-associated seizure & 3 & 525 & $0.00(-0.01,0.01)$ & 0.85 & $0 \%$ & 0.55 \\
\hline hypothermia & 2 & 843 & $0.01(-0.01,0.04)$ & 0.28 & $0 \%$ & 0.62 \\
\hline catheter infection & 4 & 1014 & $0.01(-0.02,0.04)$ & 0.36 & $31 \%$ & 0.23 \\
\hline hypotension during RRT & 3 & 652 & $0.02(-0.02,0.06)$ & 0.37 & $37 \%$ & 0.21 \\
\hline
\end{tabular}

Abbreviations: $R R T$ renal replacement therapy

of RRT initiation among studies. Urine output, serum creatinine, serum urea nitrogen and AKI stages were not used unified in the individual studies to define the early and late RRT strategies. In extreme cases, patients in the early RRT group in one study might be enrolled as late RRT in other studies. The high heterogeneity of definitions of "early" and "late" RRT between RCTs precluded the establishment of definitive conclusions. Second, most studies enrolled AKI patients with a mixed population; whereas the optimal timing of RRT initiation might be associated with the primary diseases. Moreover, the severity of the primary disease, presence of comorbid conditions, complications after surgery and fluid balance before RRT initiation could also be the possible confounders related to study outcome. Third, although the included 9 studies were all RCTs, the quality of many of them was not very high. There was a trend of publication bias towards a survival benefit from early initiation of RRT in studies with small sample sizes. In addition, different randomized methods were adopted in the individual studies, some of which were not sufficiently rigorous.
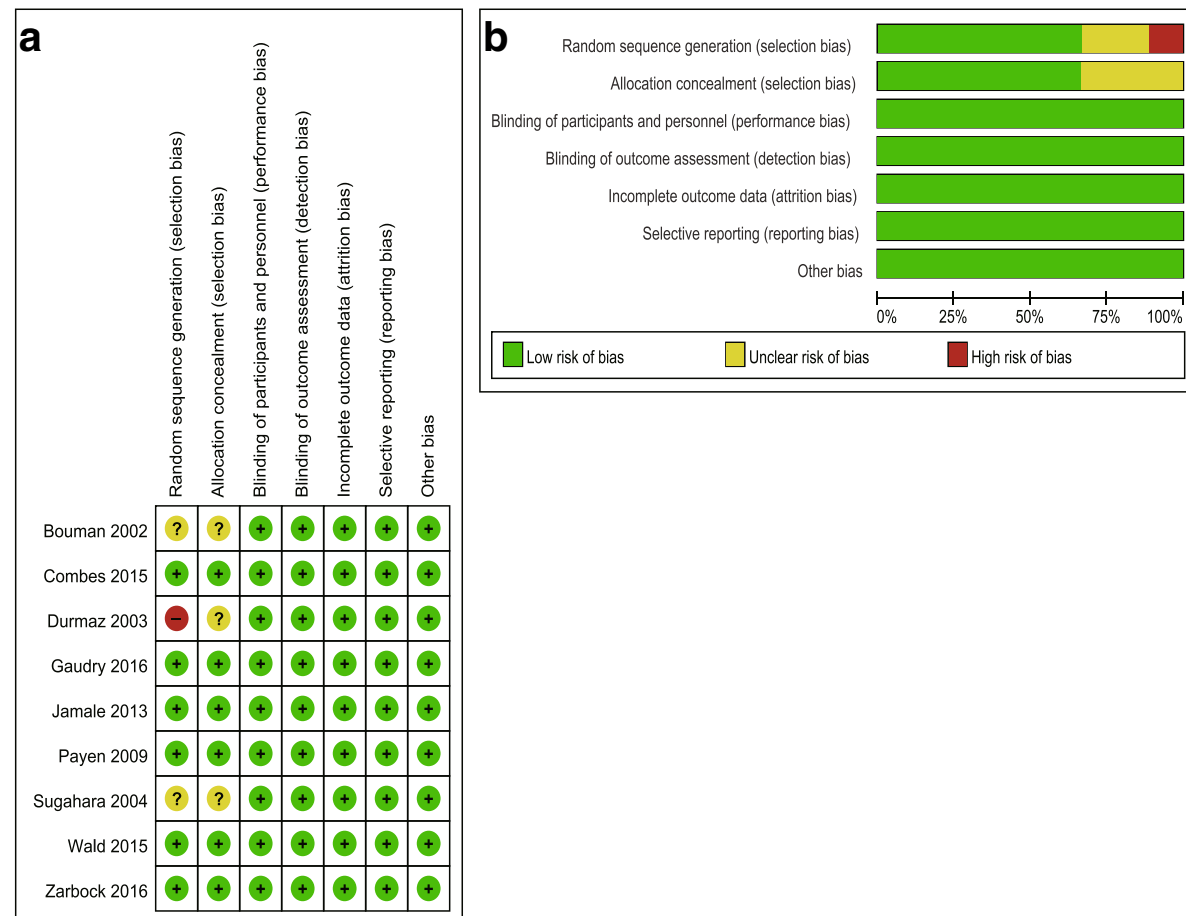

Fig. 12 a Risk of bias summary: review authors' judgments about each risk of bias item for each included study. b Risk of bias graph: review authors' judgments about each risk of bias item presented as percentages across all included studies 


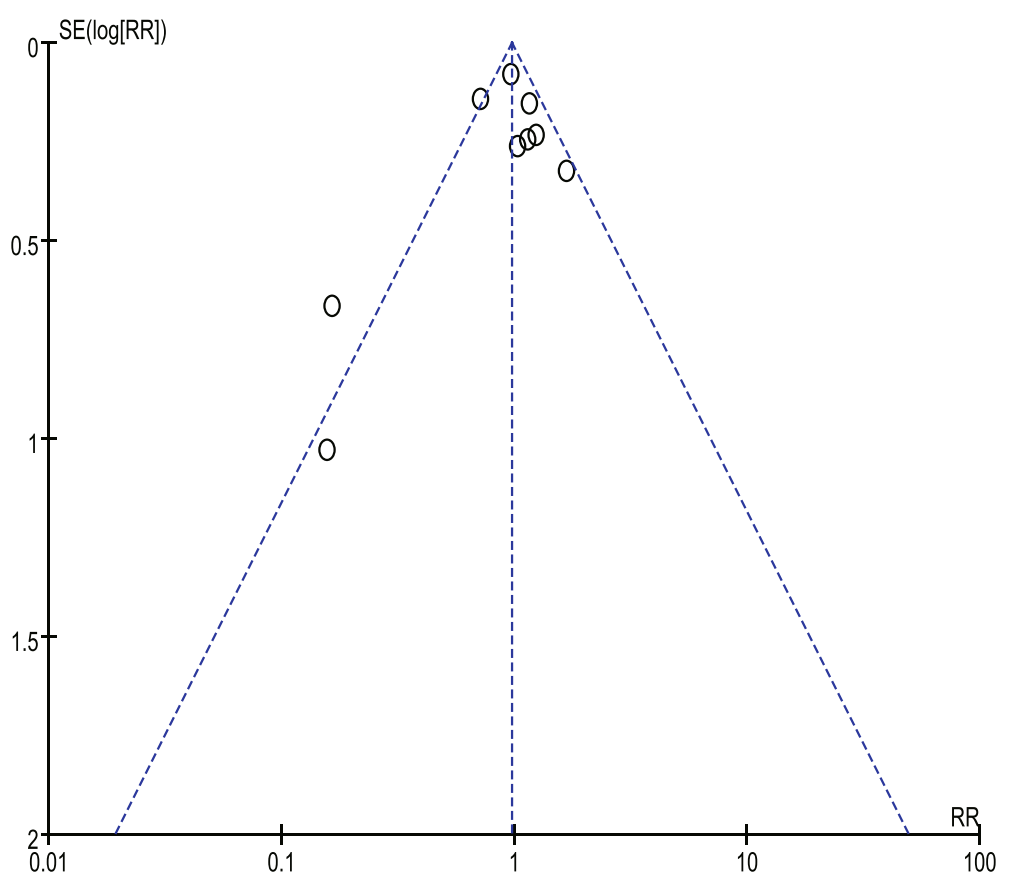

Fig. 13 Assessment of publication bias using a funnel plot

Additionally, we cannot omit the progression of the critical care medicine during the past decade. In the study conducted in patients with acute renal failure following coronary bypass surgery in 2004, the mortality was as high as $86 \%$ in the "late" group [20]. However, the HEROICS study, conducted in post-cardiac surgery shock patients in 2015 , showed that the 30-day mortality of the "early" and "late" group was only $36 \%$ [17]. We found that $5 / 6$ of the RCTs published over the past decade failed to prove the benefit of early initiation of RRT. Great progress in hemodynamic monitoring, mechanical ventilation, nutrition support and even RRT technology development has been achieved in critical care medicine in the past decade. This may also partially explain the negative results of large RCTs in recent years regarding the early goal-directed therapy in the treatment of severe sepsis and septic shock [25-27]. Therefore, studies published before 1985 were excluded in this meta-analysis.

Based on these limitations, there is no established evidence of the association between timing of RRT initiation and outcomes. Due to the relatively high heterogeneity among enrolled studies, the conclusion of the meta-analysis should be interpreted with great caution. Although we could not reach the definite conclusion in our meta-analysis, we raise several suggestions for upcoming studies: (1) enrolled patients might be in a specified population, such as sepsis or post cardiovascular surgery, avoiding mixed populations; (2) using a unified definition of the timing of early and late RRT could facilitate reaching reliable conclusions; and (3) the endpoint outcome of studies and choice of modalities of RRT should also be uniform if possible.

\section{Conclusions}

Our meta-analysis revealed that the "early" initiation of RRT in critically ill patients did not result in a reduced mortality. A pooled analysis of secondary outcomes showed no significant difference in ICU LOS or hospital LOS between early and late RRT group for survivors or nonsurvivors. A pooled analysis also demonstrated no significant change in renal function recovery, RRT dependence, renal recovery time or mechanical ventilation time. No significant differences in complications between the early and late RRT groups were found. Due to the relatively high heterogeneity among enrolled studies in this meta-analysis, the conclusion of the meta-analysis should be interpreted with great caution. More well-designed and large-scale trials are expected to confirm the result of this meta-analysis.

\section{Additional file}

Additional file 1: Table S1. Search strategy terms and results. (RTF 81 kb)

\section{Abbreviations}

AKI: Acute kidney injury; CRRT: Continues renal replacement therapy; CWH: Continuous veno-venous hemofiltration; ICU: Intensive care unit; IHD: Intermittent hemodialysis; LOS: Length of stay; RCTs: Randomized controlled trials; RRT: Renal replacement therapy 


\section{Acknowledgements}

Not applicable.

\section{Funding}

This article was supported by grants from the research funding of Zhongshan hospital (2015ZSYXGG-01), National Natural Science Foundation of China (81500067) and Shanghai Municipal Commission of Health and Family Planning (20154Y011 and 201440333).

\section{Availability of data and materials}

All data generated or analysed during this study are included in the published articles (Additional file 1: Table S1).

\section{Authors' contributions}

$X Y$ and GT performed the literature search, extracted date and drafted the manuscript. JZ, BS, GM and GH reviewed studies for inclusion and extracted data. JG performed the analysis of pooled data and helped draft the manuscript. ZL conceived the idea, participated in manuscript writing and revision. All authors have read and approved the final manuscript.

\section{Ethics approval and consent to participate}

Ethics approval and consent waived. All the data presented in this review is from previously published studies.

\section{Consent for publication}

Not applicable.

\section{Competing interests}

The authors declare that they have no competing interests.

\section{Publisher's Note}

Springer Nature remains neutral with regard to jurisdictional claims in published maps and institutional affiliations.

\section{Author details}

'Department of Critical Care Medicine, Zhongshan Hospital, Fudan University, Shanghai 200032, People's Republic of China. ${ }^{2}$ Department of Nursing, Zhongshan Hospital, Fudan University, Shanghai, People's Republic of China. ${ }^{3}$ Department of Nephrology, Zhongshan Hospital, Fudan University, Shanghai, People's Republic of China. ${ }^{4}$ Department of Nutrition, Zhongshan Hospital, Fudan University, Shanghai 200032, People's Republic of China. ${ }^{5}$ Center of Clinical Epidemiology and Evidence-based Medicine, Fudan University, Shanghai, People's Republic of China.

Received: 9 February 2017 Accepted: 14 July 2017

Published online: 07 August 2017

\section{References}

1. Clec'h C, Gonzalez F, Lautrette A, Nguile-Makao M, Garrouste-Orgeas M, Jamali S, Golgran-Toledano D, Descorps-Declere A, Chemouni F, Hamidfar-Roy R, et al. Multiple-center evaluation of mortality associated with acute kidney injury in critically ill patients: a competing risks analysis. Crit Care. 2011;15(3):R128.

2. Ea H, Sm B, Bellomo R, Cm C, Colman R, Dn C, Edipidis K, Lg F, Cd G, Govil $D$, et al. Epidemiology of acute kidney injury in critically ill patients: the multinational Aki-epi study. Intensive Care Med. 2015;41(8):1411-23.

3. Vinsonneau C, Allain-Launay E, Blayau C, Darmon M, Ducheyron D, Gaillot T, Pm H, Javouhey E, Krummel T, Lahoche A, et al. Renal replacement therapy in adult and pediatric intensive care: recommendations by an expert panel from the French Intensive Care Society (Srlf) with the French society of anesthesia intensive care (Sfar) French group for pediatric intensive care emergencies (Gfrup) the French dialysis society (Sfd). Ann Intensive Care. 2015;5(1):58.

4. Dm Y, Ja K, Huang D, Ae B, La W, Pike F, Terndrup T, He W, Pc H, Lovecchio $\mathrm{F}$, et al. A randomized trial of protocol-based care for early septic shock. $\mathrm{N}$ Engl J Med. 2014;370(18):1683-93.

5. $\operatorname{Pr} M, T m$ O, Gs P, Da H, Mz S, Rd G, Jahan R, Se H, Bell D, Jf B, et al. Trial of early, goal-directed resuscitation for septic shock. N Engl J Med. 2015;372(14): 1301-11.

6. Yang X, Tu G, Gao J, Wang C, Zhu D, Shen B, Liu L, Luo Z. A comparison of preemptive versus standard renal replacement therapy for acute kidney injury after cardiac surgery. J Surg Res. 2016;204(1):205-12.
7. Sm B, Uchino S, Bellomo R, Morimatsu H, Morgera S, Schetz M, Tan I, Bouman C, Macedo E, Gibney N, et al. Timing of renal replacement therapy and clinical outcomes in critically ill patients with severe acute kidney injury. J Crit Care. 2009:24(1):129-40.

8. Wierstra B, Kadri S, Alomar S, Burbano X, Gw B, RI K. The impact of "early" versus "late" initiation of renal replacement therapy in critical care patients with acute kidney injury: a systematic review and evidence synthesis. Crit Care. 2016;20(1):122.

9. Liu Y, Davari-Farid S, Arora P, Porhomayon J, Nd N. Early versus late initiation of renal replacement therapy in critically ill patients with acute kidney injury after cardiac surgery: a systematic review and meta-analysis. J Cardiothorac Vasc Anesth. 2014;28(3):557-63.

10. Wang $X, Y W$ J. Timing of initiation of renal replacement therapy in acute kidney injury: a systematic review and meta-analysis. Ren Fail. 2012;34(3): 396-402.

11. Cj K, Mr F, Sajjad I, Ss M, Aa L, Wald R, Sm B. A comparison of early versus late initiation of renal replacement therapy in critically ill patients with acute kidney injury: a systematic review and meta-analysis. Crit Care. 2011;15(1):R72.

12. Gaudry S, Hajage D, Schortgen F, Martin-Lefevre L, Pons B, Boulet E, Boyer A, Chevrel G, Lerolle N, Carpentier D, et al. Initiation strategies for renal-replacement therapy in the intensive care unit. N Engl J Med. 2016;375(2):122-33.

13. Zarbock A, Kellum JA, Schmidt C, van Aken H, Wempe C, Pavenstadt $H$, Boanta A, Gerss J, Meersch M. Effect of early vs delayed initiation of renal replacement therapy on mortality in critically ill patients with acute kidney injury: the Elain randomized clinical trial. JAMA. 2016;315(20):2190-9.

14. Bj B, Jackson D. The exact distribution of Cochran's heterogeneity statistic in one-way random effects meta-analysis. Stat Med. 2008;27(29):6093-110.

15. Egger M, Davey SG, Schneider M, Minder C. Bias in meta-analysis detected by a simple. Graphical Test Bmj. 1997;315(7109):629-34.

16. Payen D, Mateo J, Cavaillon JM, Fraisse F, Floriot C, Vicaut E. Impact of continuous Venovenous hemofiltration on organ failure during the early phase of severe sepsis: a randomized controlled trial. Crit Care Med. 2009; 37(3):803-10.

17. Combes A, Brechot N, Amour J, Cozic N, Lebreton G, Guidon C, Zogheib E, Thiranos JC, Rigal JC, Bastien O, et al. Early high-volume hemofiltration versus standard care for post-cardiac surgery shock. The Heroics study. Am J Respir Crit Care Med. 2015;192(10):1179-90.

18. Wald R, Adhikari NK, Om S, Ma W, Pope K, Cohen A, Thorpe K, Mcintyre L, Lamontagne $\mathrm{F}$, Soth $\mathrm{M}$, et al. Comparison of standard and accelerated initiation of renal replacement therapy in acute kidney injury. Kidney Int. 2015;88(4):897-904.

19. Durmaz I, Yagdi T, Calkavur T, Mahmudov R, Apaydin AZ, Posacioglu H, Atay $Y$, Engin C. Prophylactic dialysis in patients with renal dysfunction undergoing on-pump coronary artery bypass surgery. Ann Thorac Surg. 2003;75(3):859-64.

20. Sugahara S, Suzuki $\mathrm{H}$. Early start on continuous hemodialysis therapy improves survival rate in patients with acute renal failure following coronary bypass surgery. Hemodial Int. 2004;8(4):320-5.

21. Te J, Nk H, Kulkarni M, Pradeep KJ, Keskar V, Jawale S, Mahajan D. Earlier-start versus usual-start dialysis in patients with community-acquired acute kidney injury: a randomized controlled trial. Am J Kidney Dis. 2013;62(6):1116-21.

22. Cs B, Oudemans-Van S, Jg T, Df Z, Kesecioglu J. Effects of early high-volume continuous Venovenous hemofiltration on survival and recovery of renal function in intensive care patients with acute renal failure: a prospective. Randomized Trial Crit Care Med. 2002;30(10):2205-11.

23. Vf $\mathrm{S}$, Em B, Liangos $\mathrm{O}$, Sosa MA, Cendoroglo M, BI J. Timing of renal replacement therapy initiation in acute renal failure: a meta-analysis. Am J Kidney Dis. 2008; 52(2):272-84.

24. Wang $X$, Jie $Y W$. Timing of initiation of renal replacement therapy in acute kidney injury: a systematic review and meta-analysis. Ren Fail. 2012;34(3): 396-402.

25. SI P, Delaney A, Bailey M, Bellomo R, Cameron PA, Cooper DJ, Higgins AM, Holdgate A, Howe BD, Webb SA, et al. Goal-directed resuscitation for patients with early septic shock. N Engl J Med. 2014;371(16):1496-506.

26. Dm Y, Ja K, Huang D, Ae B, La W, Pike F, Terndrup T, Wang HE, Hou PC, Lovecchio F, et al. A randomized trial of protocol-based care for early septic shock. N Engl J Med. 2014;370(18):1683-93.

27. $\operatorname{Pr} \mathrm{M}, \mathrm{Tm} \mathrm{O}, \mathrm{Gs} \mathrm{P}, \mathrm{Da} H, \mathrm{Mz} \mathrm{S}, \mathrm{Rd} \mathrm{G}$, Jahan R, Harvey SE, Bell D, Jf B, et al. Trial of early, goal-directed resuscitation for septic shock. N Engl J Med. 2015;372(14):1301-11. 